OPEN ACCESS

Edited by:

Erics A. Singer,

Rutgers Cancer Institute of New

Jersey, United States

Reviewed by:

Eric Jonasch,

University of Texas MD Anderson

Cancer Center, United States Hiroshi Yaegashi,

Kanazawa University, Japan

*Correspondence:

Changchun Zeng

zengchch@glmc.edu.cn

Specialty section:

This article was submitted to Genitourinary Oncology,

a section of the journal

Frontiers in Oncology

Received: 27 March 2021 Accepted: 05 May 2021

Published: 25 May 2021

Citation:

Zhang C, Li L, Zhang Y and Zeng C (2021) Hereditary Leiomyomatosis and Renal Cell Cancer: Recent Insights Into Mechanisms and Systemic Treatment.

Front. Oncol. 11:686556.

doi: 10.3389/fonc.2021.686556

\section{Hereditary Leiomyomatosis and Renal Cell Cancer: Recent Insights Into Mechanisms and Systemic Treatment}

\author{
Congwang Zhang ${ }^{1}$, Lijun $L^{2}{ }^{2}$, Yipeng Zhang ${ }^{3}$ and Changchun Zeng ${ }^{1 *}$ \\ ${ }^{1}$ Department of Medical Laboratory, Shenzhen Longhua District Central Hospital, Shenzhen, China, ${ }^{2}$ Department of Quality \\ Control, Shenzhen Longhua District Central Hospital, Shenzhen, China, ${ }^{3}$ Clinical Laboratory, Shenzhen Longhua District \\ Central Hospital, Shenzhen, China
}

Hereditary leiomyomatosis and renal cell carcinoma (HLRCC) is a rare autosomal dominant hereditary cancer syndrome characterized by a predisposition to cutaneous leiomyomas, uterine leiomyomas, and renal cell carcinoma (RCC). It is known to be caused by germline mutations of the fumarate hydratase $(\mathrm{FH})$ gene, which encodes an enzyme component of the citric acid cycle and catalyzes the conversion of fumarate to Lmalate. Currently, there is no standardized treatment for HLRCC, which may be due in part to a lack of understanding of the underlying mechanisms. Here, the underlying molecular mechanisms by which the inactivation of FH causes HLRCC are discussed. Additionally, potential therapeutic pharmacological strategies are also summarized to provide new perspectives for the prevention and treatment of HLRCC.

Keywords: hereditary leiomyomatosis and renal cell carcinoma, fumarate hydratase, pathogenesis, mechanism, treatment

\section{INTRODUCTION}

Hereditary leiomyomatosis and renal cell cancer (HLRCC), also known as leiomyomatosis and renal cell cancer (LRCC), is a rare autosomal dominant disorder in which the affected individuals have a higher risk of developing cutaneous leiomyomas, uterine leiomyomas, and renal cell carcinoma (RCC) (1). HLRCC, estimated to have an estimated incidence of approximately 1 in 200,000, is caused by inactivating mutations in the fumarate hydratase (FH) gene (2-6).

Renal cell carcinoma in HLRCC was previously classified as type 2 papillary renal cell carcinoma. HLRCC is currently recognized as epithelial renal tumors in the 2016 Worldwide Health Organization (WHO) classification of renal tumors $(3,7,8)$. The penetrance of renal cancer in HLRCC is $10-20 \%$. HLRCC tends to occur at an early age of onset and presents an aggressive clinical behavior with a poor prognosis $(3,9)$. There is a tendency to develop into uterine and cutaneous leiomyomas as well as papillary RCC in individuals with HLRCC, and approximately $15 \%$ to $30 \%$ of HLRCC patients develop kidney cancer $(4-6,10,11)$. According to the latest analysis of 672 HLRCCs, $71.5 \%$ of patients had skin leiomyomas, $83 \%$ of women had uterine leiomyomas, and $34.9 \%$ of patients had RCCs (1). Furthermore, uterine leiomyomas appeared in $79 \%$ to $100 \%$ of women carrying the $\mathrm{FH}$ mutation $(6,11,12)$. 
A portion of patients with HLRCC are probably misdiagnosed as papillary RCC and treated following papillary RCC therapy (12). In addition, patients diagnosed with advanced HLRCC lack effective treatment strategies (13). There is a current shortage of FDA-approved medications for HLRCC. HLRCC is classified as non-clear cell carcinoma, of which the subtypes are diverse, difficult to diagnose, and relatively infrequent. In NCCN guidelines and clinical practice, patients with HLRCC will be treated with conventional clear cell carcinoma medications, such as vascular endothelial growth factor receptor (VEGFR) tyrosine kinase inhibitors (TKIs), mammalian target of rapamycin (mTOR) inhibitors, and immune checkpoint inhibitors (14, 15). However, clear cell renal carcinoma (ccRCC) and nonRCC have completely different genetic characteristics, and different pathological types of no-RCC have different clinical characteristics and drug responses (16). As a result, conventional medications for the treatment of ccRCC are not particularly effective for HLRCC, and alternative treatment options for HLRCC are urgently needed. Elucidation of the underlying mechanisms involved in the progression of HLRCC may reveal underlying therapeutic targets that may provide new information on the management of $\operatorname{HLRCC}(5,17)$.

The FH gene located at 1q42.3-q43 encodes an enzyme component involved in the tricarboxylic acid (TCA) cycle, which facilitates the formation of L-malate from fumarate (18, 19). FH inactivation results in decreased oxidative phosphorylation and metabolic reprogramming to aerobic glycolysis, also known as the "Warburg effect" $(20,21)$. The mutated FH eliminates the hypoxia-inducible factor (HIF) prolyl-hydroxylase and enhances the hypoxia-inducible factor 1 alpha (HIF1alpha), which further affects downstream effectors, such as glucose transporter 1, erythropoietin, and vascular endothelial growth factor, and induces epigenetic changes, causing cell proliferation, metastasis, and tumor. In addition, the inactivation of $\mathrm{FH}$ contributes to the accumulation of fumarate, which increases oxidative stress and stimulates the signaling pathway of NRF2-antioxidant response elements (14, 17, 22).

The purpose of this study is to summarize recent advances in the molecular mechanism of HLRCC and to describe the potential treatment strategies for HLRCC to assist clinicians in managing HLRCC.

\section{PATHOGENESIS}

\section{FH Inactivation and the Activation of HIF}

$\mathrm{FH}$ inactivation was confirmed to be associated with the initial tumor-promoting event in HLRCC, leading to decreased $\mathrm{FH}$ enzyme function. As shown in Figure 1, FH inactivation contributes to the activation of the hypoxia-inducible factor (HIF), which is generally comprised of $\alpha$ and $\beta$ subunits and functions as an oxygen sensor (23). Under physiological oxygen levels, HIF prolyl hydroxylases (PHDs) work with oxygen (O2), 2-oxoglutarate (2-OG), ascorbic acid, and iron $(\mathrm{Fe} 2+)$ to hydroxylate specific proline residues within the oxygendependent degradation domain (ODD) of HIF- $\alpha$ subunits, causing HIF ubiquitination. Subsequently, HIF is recognized by von Hippel-Lindau tumor suppressor protein (pVHL) and degraded by the proteasome $(24,25)$.

In tumor cells, HIF activation is incredibly essential to coordinate its adaptation to hypoxic conditions $(26,27)$. HIF-1 regulates metabolic transformation by modulation of the activity of GLUTs participants in glycolysis. In glycolysis, glucose is ultimately converted to pyruvates, ATP, and NADH, and the pyruvate is subsequently applied in the tricarboxylic acid cycle or works as a precursor implicated in other reactions (28). GLUTs contribute to glucose absorption and accelerate the metabolic shift towards glycolysis in glucose metabolism, causing increased glucose absorption in hypoxic cancer cells (29-31). In hypoxia, $\mathrm{HIF} \alpha$ is incapable of being hydroxylated and evades pVHL recognition, which causes HIF $\alpha$ to accumulate. HIF $\alpha$ migrates to the cellular nucleus and subsequently interacts with HIF-1 $\beta$ to form a HIF-complex, which binds to the DNA and initiates a transcriptional program to counter hypoxia $(14,32,33)$. HIF-1 $\alpha$ can bind with enhancers or promoters of the target genes and activate and modulate the transcription of target genes. Various target genes, such as vascular endothelial growth factor (VEGF), erythropoietin (EPO), epidermal growth factor (EGF), transforming growth factor beta3 (TGF- $\beta 3$ ), and glucose transporters (GLUTs) are critical to cancer development (29, 33). HIF-1 acts as a transcription factor of VEGF and supports vessel formation, which is essential for tumor growth, and angiogenesis (34-36). Additionally, inhibiting HIF-1 is responsible for the decreased secretion of VEGF and suppresses tumor growth.

The decreased activity of prolyl hydroxylases induces the accumulation of HIF- $1 \alpha$. Loss of FH can induce reactive oxygen species (ROS) by inhibiting the activity of prolyl hydroxylases, which may contribute to the stabilization of HIF$1 \alpha(10)$. Antioxidants can inhibit increases in ROS, and the high levels of ROS may lead to constitutive activation of HIF. Moreover, HIF activation can not only eliminate the formation of ROS by blocking the TCA cycle but also enhance ROS formation via NADPH oxidase (37-39). ROS involved in tumor formation accumulates in tumors with $\mathrm{FH}$-deficient, and high levels of ROS cause the accumulation of HIF $\alpha$ (23, $40,41)$. Iron oxidation is the mechanism by which ROS stabilizes HIF. Ferrous iron $(\mathrm{Fe} 2+)$ was oxidized in ferric form $(\mathrm{Fe} 3+)$ with hydrogen peroxide, and $\mathrm{Fe} 2+$ loses the ability to bond with PHDs, which is crucial for HIF labeling for VHL-mediated HIF ubiquitination and proteasomal degradation (42, 43). Additionally, HIF PHD inhibitors enhance HIF concentrations and reduce ROS formation, indicating the potential therapeutic value of HIF PHD inhibitors (38).

\section{Epithelial to Mesenchymal Transition}

Epithelial to mesenchymal transfer (EMT) refers to the transformation of epithelial cells into mesenchymal cells. EMT results in epithelial cells losing their adhesion after polarization and acquiring the mesenchymal cell phenotype. The EMT process is involved in a variety of metabolic pathways, such as the TCA cycle, glycolysis, and lipid metabolism, associated with the development and progression of cancer (44-46). In addition 


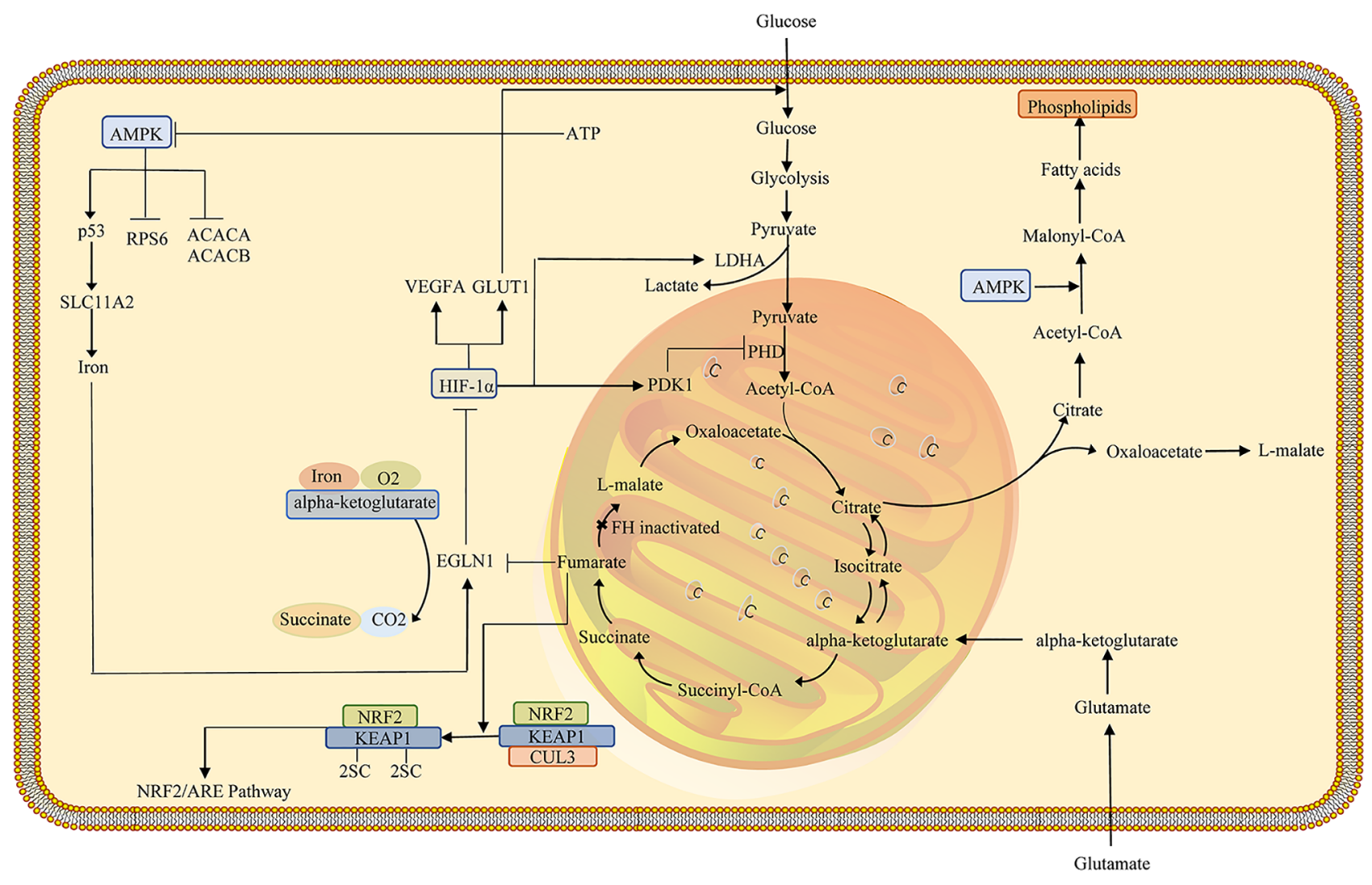

FIGURE 1 | Schematic representation of HLRCC pathway. HLRCC, marked by defective oxidative phosphorylation, undergoes a metabolic transition to aerobic glycolysis to produce ATP required for the energetic requirements of proliferating cells. Enhanced glycolysis represses AMPK expression and activation, resulting in increased S6 and ACC activity, fostering anabolic growth and proliferation. Decreased AMPK yields decreased p53 and iron transporter DMT1. Cytosolic iron concentrations will suppress prolyl hydroxylase, which is susceptible to iron levels, stabilizing HIF1 $\alpha$. Fumarate, which rises in FH-deficient cells, has been shown to suppress prolyl hydroxylase, which will contribute to more stabilization of HIF1 $\alpha$, enhancing the transcription of factors such as VEGF and GLUT1. Enhanced fumarate was shown to succinate KEAP1, thereby altering its conformation and affecting its capacity to cause Nrf2 degradation. Nrf2 transcription activates antioxidant reactions and protects against oxidative stress. Increased HIF1 $\alpha$ will stimulate LDHA, increase lactate development, and stimulate PDK1, which inhibits PHD and decreases pyruvate entry into the TCA cycle. HLRCC utilizes glutamine-dependent reductive carboxylation to form citrate. HLRCC, hereditary leiomyomatosis and renal cell carcinoma; FH, fumarate hydratase; AMPK, AMP-activated protein kinase; PHD, prolyl hydroxylase; PDK1, pyruvate dehydrogenase kinase 1.

to metabolic disruption, fumarate accumulation appears to reinforce EMT, a pro-oncogene and pro-metastatic process by which epithelial cells are converted into mesenchymal cells (Figure 2) (47). As previously mentioned, fumarate can suppress HIF prolyl hydroxylases, members of the dioxygenase family, utilizing 2-OG and oxygen as co-substrates, as well as ascorbate and iron as cofactors (48). In addition, Ten-Eleven Translocation (TET) enzymes that are involved in epigenetic regulation can catalyze the oxidation of 5-methylcytosine to 5hydroxymethylcytosine oxidized $(5-\mathrm{hmC})$, leading to the demethylation of DNA $(49,50)$. Fumarate acts as a TETs inhibitor that can reduce the levels of $5-\mathrm{hmC}$, indicating the underlying epigenetic effect of fumarate (51). FH-deficient cells exhibit mesenchymal characteristics. Fumarate induces EMT in $\mathrm{FH}$-proficient cells. FH deficiency is associated with an EMT signature in HLRCC. These findings indicate that dysregulation of $\mathrm{FH}$ activity and fumarate accumulation contribute to the induction of EMT and the aggressive characteristics of
FH-deficient tumors $(47,52)$. Vimentin mediates the expression of various transcription factors related to EMT in FH-deficient cells, which may be inhibited by miRNAs, such as the miR-200 family (53). Furthermore, miR-200 was found to be extensively regulated downwards in $\mathrm{FH}$-deficient cells, consistent with the consensus of previous studies that methylation of miRNA-200 in the promoter region is modulated by TET demethylation $(44,47,54)$. The results imply that $\mathrm{FH}$ loss and fumarate accumulation exert a vital part in EMT induction, leading to hypermethylation and miR-200 inhibition (47).

\section{DNA Damage Repair}

Recent research suggests that fumarase and its associated metabolite fumarate are involved in the cellular DNA damage response. The biallelic inactivation of fumarase can suppress fumarate generation and decrease genomic stability $(55,56)$. Ionizing radiation induces phosphorylation of $\mathrm{FH}$ and stimulates its binding to the DNA double-strand break (DSB) region, which can bind to the DNA- 


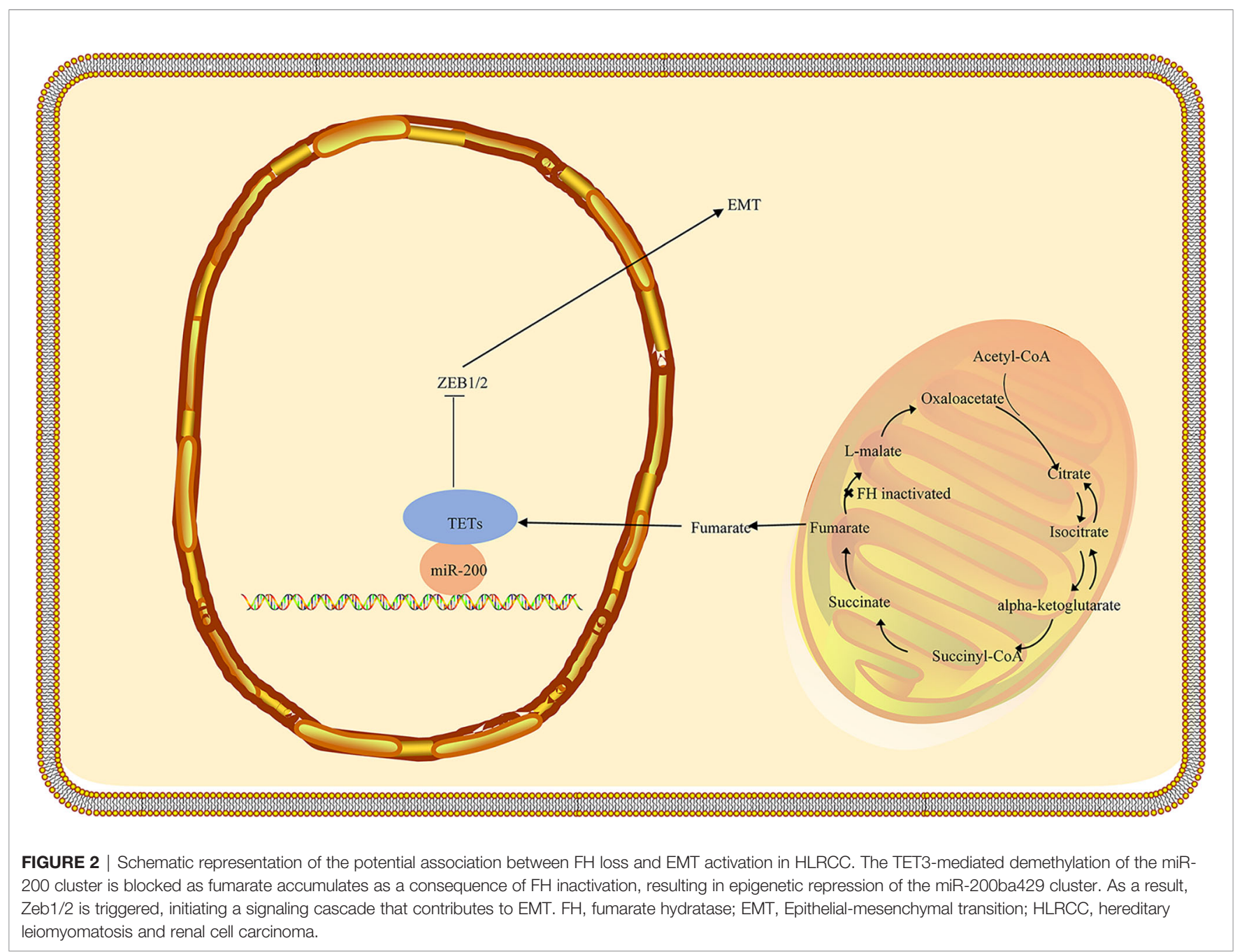

dependent protein kinase (DNA-PK) holoenzyme and cause DNAPK catalytic subunit (DNA-PKcs) activation in non-homologous end joining (NHEJ) $(57,58)$. Accumulated fumarate generation suppresses the activity of KDM2B in DSB regions, elevates H3K36me2 levels, and accumulates DNA-PK complex in DSBs for $\operatorname{NHEJ}(59,60)$. DNA-PK-mediated fumarase phosphorylation facilitates fumarate-induced DNA repair by demethylation of histone $\mathrm{H} 3$, suggesting the significant role of $\mathrm{FH}$ in repairing DNA damage (Figure 3) (58, 61-63). The fumarate accumulated in HLRCC inhibits homologous recombination (HR) and accelerates double-stranded DNA breaks by suppressing lysine demethylase, KDM4B, a member of the KMD4 family of histone demethylase, closely associated with DNA damage $(61,64)$. Additionally, $\mathrm{FH}$ loss is responsible for the resistance to ionizing radiation and motivates the early mitotic entry after ionizing radiation. Moreover, fumarate accumulation facilitates G2-M transition and causes a decrease in the G2 checkpoint, which tends to damage the DNA and confers resistance to ionizing radiation in $\mathrm{FH}$-deficient cells, indicating that $\mathrm{FH}$ loss and fumarate accumulation can give rise to genomic instability that can trigger HLRCC formation (58).

\section{The KEAP1-NRF2 Pathway in FH-Deficient Kidney Cancer}

Some studies have suggested that the irreplaceable role of the Kelchlike ECH-associated protein 1 (KEAP1)/nuclear factor E2-related factor 2 (Nrf2) pathway in tumor metabolism (65). Loss of enzymatic activity in fumarate hydration results in fumarate accumulation and further to the succination of Keap1 cysteine residues (2SC) (66). Previous studies have shown that the high level of fumarate accumulated in HLRCC tumor cells causes aberrant succination of cellular proteins by forming a stable chemical modification, S-(2-succino)-cysteine (2SC), detectable by immunohistochemistry. Most confirmed HLRCC tumors showed diffuse and strong staining of nuclear and cytoplasmic 2SC, while all clear cells, most high-grade unclassified RCC, and the large majority of type 2 papillary cases showed no 2SC immunoreactivity (67). FH and $2 \mathrm{SC}$ are two highly correlated immunohistochemical biomarkers in the HLRCC diagnosis (68). NRF2, a member of a small family of basic leucine zipper (bZIP) proteins, encoded by the nuclear factor, erythroid derivative two like 2 (NFE2L2) gene, is a transcription factor that affects oxidative and electrophilic stress. $\mathrm{NRF} 2$ can bind to antioxidant response (ARE) elements in the 


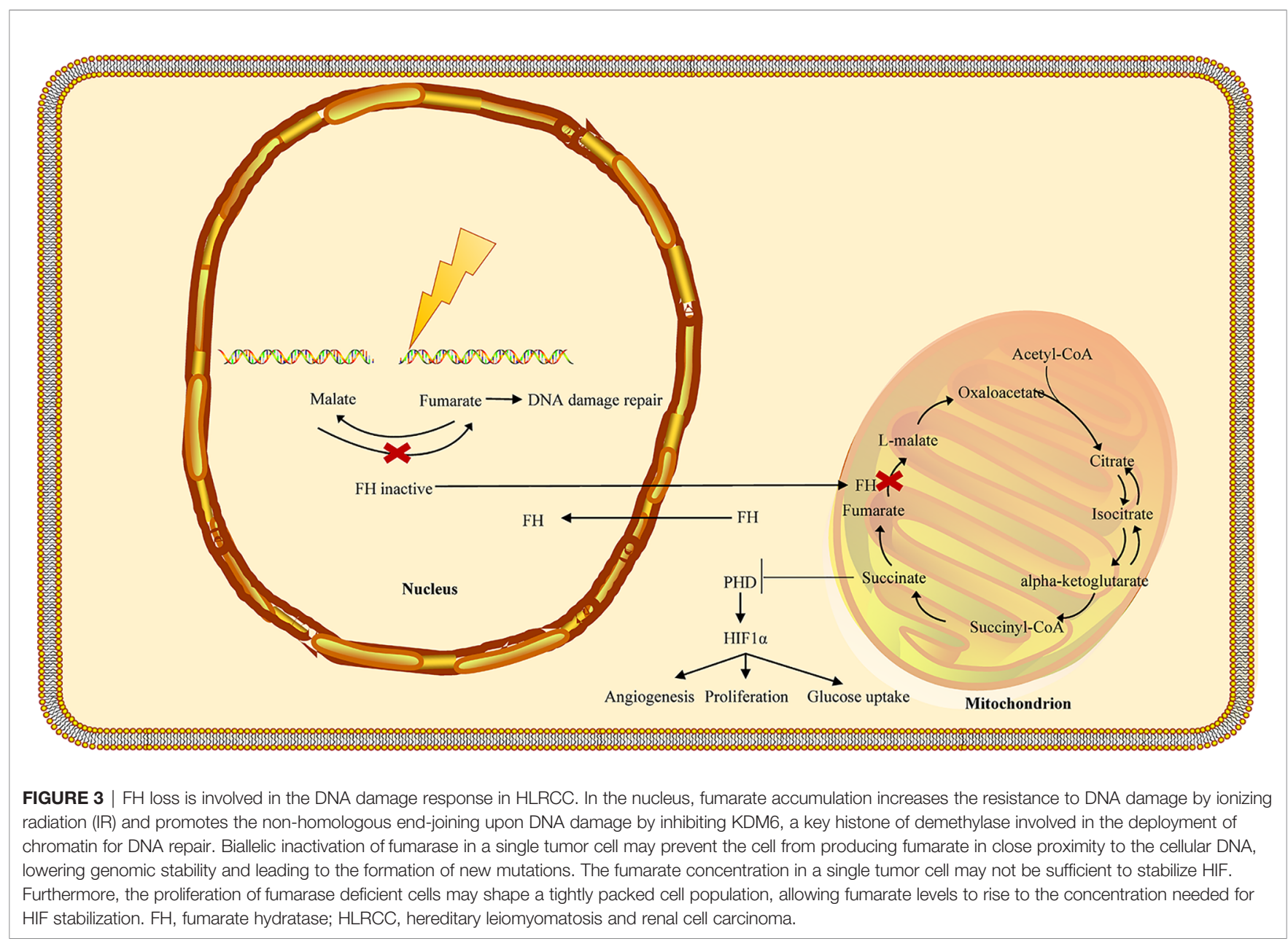

promoter region of various genes (69). Accumulating evidence suggests that the controlled activation of NRF2 can eliminate reactive-oxygen species (ROS) and weaken DNA damage, thereby reducing the probability of cancer onset and progression in normal cells. However, in transformed cells, activation of NRF2 signaling is associated with an unfavorable prognosis and leads to malignant progression (Figure 4) (70). Under normal conditions, KEAP1 regulates the stability of the NRF2 protein through proteasomal degradation. NRF2 interacts with the KEAP1 complex in the cytoplasm, and NRF2 is continuously ubiquitinated and degraded to ensure low levels of NRF2 and avoid the activation of its target genes. Under stressed conditions, oxidative/electrophilic stress induces a conformational change in the KEAP1 complex and contributes to the dissociation of the NRF2 from KEAP1 and the translocation of the NRF2 into the nucleus. The NRF2 accumulated in the nucleus forms heterodimerization with small MAF proteins and further binds to the ARE components of the target genes and promotes the expression of the target genes (71).

The target genes of Nrf2 possess antioxidant properties and motivate the cellular reaction to eliminate xenobiotics. Multiple antioxidant enzymes such as peroxiredoxin $1(\operatorname{Prdx} 1)$, heme oxygenase-1 (HO-1), superoxide dismutase-1 (SOD-1), and $\mathrm{NAD}(\mathrm{P}) \mathrm{H}$ dehydrogenase quinone 1 (NQO1) and various enzymes such as glutamate-cysteine ligase modifier (GCLM) and glutathione S-transferases (GSTs) participate in the synthesis of glutathione. Additionally, the target genes of Nrf2 have cytoprotective properties, exhibiting anti-inflammatory activity, and accelerating the degradation of proteins oxidatively damaged by the proteasome. Activating Nrf2 facilitates Nrf2 expression and accelerates cellular stress reactions (72-74). Furthermore, fumarate accumulation may contribute to regulating the stability of NRF2 by glutathione succination. Moreover, NRF2 activation activated by FH loss is a result of oxidation-reduction imbalance attributed to glutathione succination in FH-deficient cells (75). Sustained activation of NRF2 has been observed in HLRCC, caused by the accumulation of fumarate, which may be attributable to FH inactivation (76). Moreover, somatic mutations in NRF2, SIRT1, and CUL3 may activate NRF2 and affect NRF2 transcription activity (77).

\section{SYSTEMIC TREATMENT OF HLRCC}

\section{Bevacizumab and Erlotinib}

In HLRCC, HIF accumulation leads to the disruption of multiple signaling pathways associated with malignant progression. 


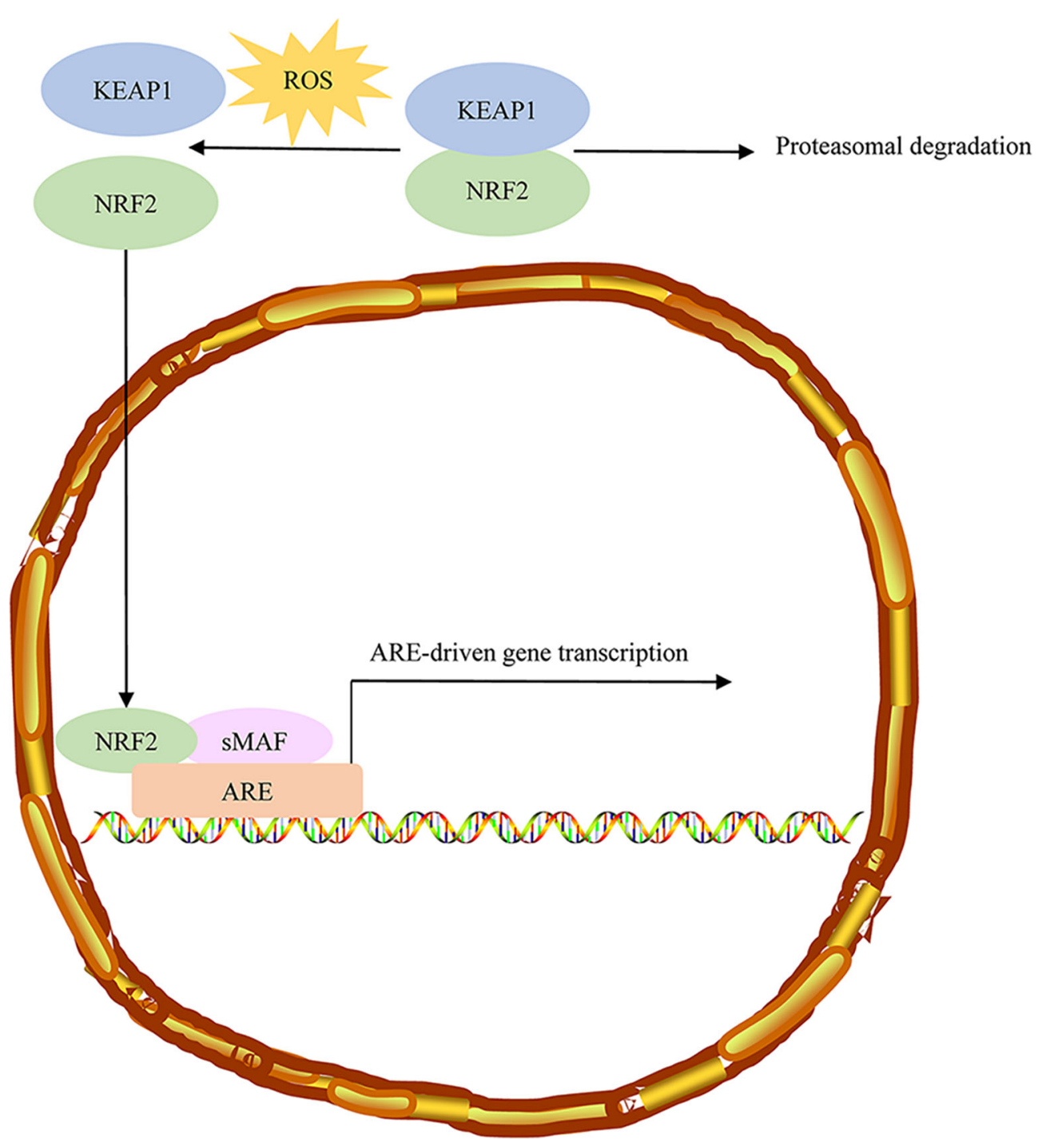

FIGURE 4 | Sustained NRF2 activation in HLRCC. Under normal conditions, NRF2 associates with the Cul3-Rbx1 E3 ubiquitin-ligase substrate KEAP1, which keeps NRF2 primed for ubiquitination and proteasomal degradation. ROS stress induces conformational changes in KEAP1, resulting in NRF2 dissociation. Free NRF2 reaches the nucleus, where it forms dimers with small MAF proteins and binds to AREs regulatory sequences of target genes. NRF2, Nuclear factor erythroid 2-related factor 2; HLRCC, hereditary leiomyomatosis and renal cell carcinoma; AREs, antioxidant responsive elements.

FH inactivation causes VHL-independent HIF upregulation and NRF2 activation. Therefore, targeting these critical downstream pathways or the pivotal pathway components, such as vascular endothelial growth factor (VEGF), transforming growth factoralpha (TGF- $\alpha$ ), and epidermal growth factor receptor (EGFR) may inhibit tumorigenesis.

Erlotinib, an inhibitor of EGFR tyrosine kinase, has been approved by FDA for the treatment of advanced or metastatic non-small cell lung cancer patients with EGFR exon 19 deletions or exon 21 (L858R) substitution mutations. Bevacizumab, a VEGF inhibitor, is widely used in a variety of cancers, such as non-small cell lung cancer, renal cell carcinoma, cervical cancer, peritoneal cancer, epithelial ovarian cancer, fallopian tube cancer, and glioblastoma.
A phase II clinical trial of bevacizumab (a humanized antiVEGF monoclonal IgG1 antibody) plus erlotinib (an inhibitor of EGFR tyrosine kinase) in patients with HLRCC (AVATAR trial, https://clinicaltrials.gov/ct2/show/NCT01130519) exhibited that the objective response rate (ORR) was $65 \%$ and the median progression-free survival (PFS) was 24.2 months in patients with HLRCC. According to this impressive study, the National Comprehensive Cancer Network (NCCN) guidelines recommended this treatment regimen to treat HLRCC (78). Additionally, a recently updated AVATAR trial result indicated that the ORR was $64 \%$ (27/42; 95\% confidence interval [CI], 49 to 77 ), and the median PFS was 21.1 months in type 2 papillary RCC subgroup associated with HLRCC (79). 
A real-world outcome of the combination of bevacizumab plus erlotinib subjects in South Korea with HLRCC exhibited that the ORR was 50\% (5/10; 95\% CI, 24 to 76) and the disease control rate was $90 \%(9 / 10 ; 95 \%$ CI, 60 to 98$)$ (78). Besides, after treatment failure with axitinib, bevacizumab plus erlotinib received a sustained response of over 18 months in a patient with locally advanced HLRCC (80). In a nutshell, the combination of bevacizumab and erlotinib may be an effective treatment for advanced HLRCC (Table 1).

\section{PARP Inhibition}

Synthetic lethality is a condition where simultaneous deficiencies in the two or more genes from complementary pathways lead to the death of cancer cells. The genetic interaction between members of the BRCA and PARP pathway can be depicted as synthetic lethality. Mutations in the members of the BRCA pathway lead to a defective HR pathway, causing tumor cell injury in the presence of PAPR inhibitors. If mutations in the BRCA genes cause loss of function of the BRCA1 and BRCA2 proteins, they cause HRD (homologous recombinant deficit). Additionally, other HRR-related genes, such as PALB2, CDK12, RAD51, CHEK2, ATM mutations, or BRCA1 gene promoter methylation, and other obscure reasons will cause HRD and cause genome instability. PARP is a crucial protein in the base excision repair (BER) pathway, participated in the repair of DNA single-strand breaks (SSBs). When the BER pathway has undergone alterations, improperly repaired SSBs accumulate and degenerate to double-strand breaks (DSBs), resulting in increased dependence on other repair pathways, such as homologous recombination (HR) and the non-homologous end joining (NHEJ) $(81,82)$. Recombinant homologous repair (HRR) is an important way to repair double-strand DNA damage. HRR is a complex multi-step signal pathway, including key proteins BRCA1 and BRCA2 (83-85).

The FDA has approved several PARP inhibitors, such as rucaparib, olaparib, niraparib, and talazoparib for the treatment of advanced cancers carrying BRCA1/2 mutations, mainly including breast, ovarian, fallopian tube, or primary peritoneal, prostate, and pancreatic cancer. In terms of mechanism of action, tumor cells with homologous recombinant defect (HRD) are more sensitive to platinum medicines or PARP inhibitors. However, it is not sufficient to use BRCA1/2 as the HRD classification standard, as there are already dozens of genes

TABLE 1 | Summary of the underlying therapeutic strategies.

\begin{tabular}{|c|c|c|}
\hline $\begin{array}{l}\text { Underlying therapeutic } \\
\text { strategies }\end{array}$ & Targets & References \\
\hline Bevacizumab and Erlotinib & VEGF; EGFR & $(78-80)$ \\
\hline PARP Inhibition & PARP & (61) \\
\hline Vandetanib and Metformin & $\begin{array}{l}\text { EGFR, VEGFR, RET, BRK, TIES2, } \\
\text { EPH, SRC; AMPK }\end{array}$ & (98) \\
\hline Sintilimab and Axitinib & PD-1; VEGFR-1,-2,-3 & $(107)$ \\
\hline Nivolumab and Axitinib & PD-1; VEGFR-1,-2,-3 & $(106)$ \\
\hline Nivolumab and Ipilimumab & PD- $1 ;$ CTLA-4 & $(108)$ \\
\hline Cabozantinib & $\begin{array}{l}\text { MET, VEGFR-1, -2, -3, AXL, RET, } \\
\text { ROS1, TYRO3, MER, KIT, TRKB, } \\
\text { FLT-3, and TIE-2 }\end{array}$ & $(110)$ \\
\hline
\end{tabular}

involved in HRR, and abnormalities of these genes can also lead to the HRD phenotype $(86,87)$. In October 2019, the FDA approved niraparib for patients with advanced ovarian, fallopian tube, or primary peritoneal cancer treated with three or more prior chemotherapy regimens and whose cancer is associated with positive HRD status. HRD is defined as either a deleterious or suspected BRCA mutation or genomic instability in patients whose disease progression is greater than six months after the response to the last platinum chemotherapy.

As previous research has shown, $\mathrm{FH}$ loss is closely associated with DNA damage repair, indicating a potential clinical benefit of poly (ADP-ribose) polymerase (PARP) inhibitors in HLRCC treatment (58). Ionizing radiation, etoposide, mitomycin $\mathrm{C}$, and cisplatin as DNA damaging agents can cause DNA damage and inhibit the survival of the FH-deficient cells. Moreover, FH loss, as well as fumarate intake, enhanced sensitivity to the PARP inhibitors, such as BMN-673, and olaparib, which are known to affect homologous recombination deficiency (HRD) tumors. Furthermore, elevated sensitivity to PARP inhibitors has been discovered in both HLRCC cell models and tumor xenograft models. Excessive production of fumarate in HLRCC undermines homologous recombination (HR) and makes FHdeficient cells highly susceptible to PARP inhibitor (61).

Recent work has highlighted that elevated fumarate leads to G2 checkpoint abrogation and further increases endogenous damage. The error-prone non-homologous end-joining (NHEJ) and continuous cell divisions further cause genomic instability and increase susceptibility to the combination of kinase inhibitors PARP and WEE1 which may suppress the G2-M checkpoint arrest and improve the therapeutic efficacy of olaparib (88). Briefly, preclinical studies have shown that PARP inhibitors are promising therapeutic agents in HLRCC treatment, but more clinical evidence is required to support this conclusion.

\section{DNA Hypermethylation}

In FH-deficient cells, the accumulated fumarate leads to the suppression of the Ten-eleven translocation (TET) enzymes which are 2-oxoglutarate (2-OG)-dependent dioxygenases. TET enzymes, catalyzing the oxidation of 5-methylcytosine DNA $(5 \mathrm{mC})$ to 5-hydroxymethylcytosine $(5 \mathrm{hmC})$, accelerate the demethylation of DNA that may affect transcriptional control. DNA methylation, a common epigenetic modification, is widely known to facilitate tumorigenesis $(89,90)$. DNA methyltransferases (DNMT) are responsible for the methyltransfer reaction, which catalyzes the transfer of S-adenosyl methionine (SAM) methyl groups to DNA and modifies gene transcription. DNMT inhibitors suppress DNA methylation and mitigate the impact of abnormal epigenetic changes in cancer (91-94). SGI-110 (guadecitabine), a second-generation DNA hypomethylating agent composed of endogenous nucleoside deoxyguanosine and decitabine, is specially designed to alleviate degradation by protein aminases and increase the effect of the active decitabine metabolite on tumor growth (95, 96). A phase II study (https://clinicaltrials.gov/ct2/show/ NCT03165721) designed to assess the clinical value of guadecitabine in patients with HLRCC showed that the enrolled HLRCC patient did not receive a complete or partial 
response. Another patient with HLRCC died as a result of disease progression (97). In general, the clinical activity and toxicity of guadecitabine in HLRCC seem unsatisfactory.

\section{Vandetanib and Metformin}

Vandetanib, a selective inhibitor of the vascular endothelial growth factor receptor (VEGFR), epidermal growth factor receptor (EGFR), and Ret Proto-Oncogene (RET) tyrosine kinases, is widely used in treating patients with advanced or metastatic medullary thyroid cancer. Both the EGFR- and VEGFRdependent pathways are identified as one of the critical processes in tumor growth and metastasis. Activation of RET receptor tyrosine kinase (RTK) triggers multiple signaling pathways, suggesting that inhibition of RET activity may delay tumor progression. As described in previous studies, vandetanib has been shown to inhibit ABL1 activity that demonstrated synthetic lethality with FH $(98,99)$. ABL proto-oncogene 1, Non-Receptor Tyrosine Kinase (ABL1) is a member of the ABL family of nonreceptor tyrosine kinases implicated in multiple cellular processes, such as cell motility and adhesion, DNA damage response, autophagy, and differentiation (100, 101). In UOK262 cells, vandetanib, as inhibition of $\mathrm{ABL} 1$, is responsible for a gradual decrease in HIF1 $\alpha$ expression and mammalian target of rapamycin (mTOR) activity, and the cells sensitive to vandetanib are dependent on ABL1 activity. Moreover, elevated expression of ABL1 was recognized in human tumor samples compared to normal renal tissue. Also, ABL1 contributes to aerobic glycolysis, and vandetanib can inhibit glycolysis and delay tumor progression. Besides, the inhibition of ABL1 appears to facilitate the transfer of NRF2 from the nucleus to the cytoplasm and lead to diminished transcription of its target genes, indicating a vital role of ABL1 in the regulation of the KEAP1/NRF2 pathway.

AMP-activated protein kinase (AMPK) activator metformin reduced NRF2 acetylation, and the combination of metformin and vandetanib resulted in an additive inhibition of NRF2 in UOK262 cells. Compared with the administration of a single vandetanib agent, the addition of a clinically achievable dose of metformin decreased the effective concentration of vandetanib by 90\% in an HLRCC xenograft model. Metformin regulates AMPK, vandetanib inhibits $A B L 1$, and the combination of metformin and vandetanib may inhibit NRF2 activity to the maximum extent in vitro (98). In UOK262 cells, the attenuation of AMPK activity causes metabolic alternations. Activating AMPK facilitates the expression of the silent information regulator T1 (SIRT1) in a vandetanib independent manner, leading to the deacetylation and suppression of NRF2. A combination of vandetanib and metformin contributes to a decrease in the KEAP1/NRF2 pathway activity in HLRCC (98). Besides, a phase I/II trial (https://clinicaltrials.gov/ct2/ show/NCT02495103) of vandetanib in combination with metformin in subjects with HLRCC is underway, and the effectiveness of this therapeutic strategy deserves to be evaluated.

\section{Checkpoint Inhibitor Immunotherapy}

The United States Food and Drug Administration (FDA) has approved PD-1 inhibitors (nivolumab and pembrolizumab) and PD-L1 inhibitors (atezolizumab, avelumab, and durvalumab) in combination with other regimens for metastatic RCC. However, there is a current shortage of FDA-approved medications for HLRCC. HLRCC is classified as non-clear cell carcinoma, which has a variety of subtypes that are difficult to diagnose and relatively low incidence. In the NCCN guidelines and actual clinical practice, patients with HLRCC will be treated with drugs against clear cell carcinoma. Importantly, there are some case reports of immune checkpoint inhibitors showing promising results, and clinical trials involving immune checkpoint inhibitors are underway, suggesting that immune checkpoint inhibitors may be a promising therapeutic target in HLRCC. Therefore, for advanced or metastatic HLRCC patients, participating in relevant clinical trials is a treatment strategy that may be considered. However, there is minimal information on the potential therapeutic implications of immune checkpoint inhibitors in the treatment of patients with HLRCC (102-104).

Recently, the expression of PD-1/PD-L1 in 13 HLRCC is assessed for the first time using immunohistochemistry (IHC) and quantitative polymerase chain reaction (qPCR), and the results have shown that PD-1/PD-L1 expression is limited to a small proportion of HLRCC patients, who are more likely to benefit from immunotherapy (105). Moreover, a single-arm phase II clinical trial (https:/clinicaltrials.gov/ct2/show/NCT04146831) to assess the safety and efficacy of sintilimab (a PD-1 inhibitor) as second-line treatment in HLRCC is going. Besides, a single-arm phase II clinical trial (https://clinicaltrials.gov/ct2/show/NCT04387500) to assess the safety and efficacy of sintilimab (a PD-1 inhibitor) in combination with axitinib (a VEGFR1/2/3 inhibitor) in HLRCC is also currently underway. Furthermore, one case of metastatic HLRCC achieved long-term survival with cytoreductive nephrectomy, followed by a sequence of axitinib and nivolumab (106). Another case of recurrent and metastatic HLRCC achieved acceptable efficacy from the association of sintilimab and axitinib (107). The combination of nivolumab (a PD-1 inhibitor) and ipilimumab (an inhibitor of CTLA-4) demonstrates promising therapeutic perspectives in a variety of tumor types. The FDA has approved the combination of nivolumab and ipilimumab for the treatment of metastatic ccRCC. Additionally, after 31 weeks of combined nivolumab and ipilimumab, a patient with HLRCC achieved a complete response (108). The PD1/PD-L1 interaction occurs primarily in surrounding tissues and organs and primarily plays a role in the effective stage of $\mathrm{T}$ cell activation. CTLA-4 is expressed by Treg cells and memory CD4+ cells and plays a role in the early activation of $\mathrm{T}$ cells in lymphoid tissues (109). Taken together, it seems possible to consider combining immunotherapy with a targeted treatment for HLRCC.

\section{Others}

Cabozantinib has been approved for patients with metastatic renal clear cell carcinoma. However, studies on the safety and efficacy of cabozantinib in non-clear-cell RCC treatment are relatively limited, especially in HLRCC. A multicenter retrospective cohort study of 112 patients with advanced nonclear-cell renal cell carcinoma treated with cabozantinib was conducted to investigate the activity and toxicity of cabozantinib in the advanced non-clear-cell RCC. FH mutations were present in five patients with non-clear-cell RCC. Among them, one 
patient with collecting duct carcinoma and two patients with papillary cell carcinoma achieved a partial response, while the remaining two patients achieved stable disease, suggesting that cabozantinib seems to be effective for HLRCC (110).

2-deoxy-D-glucose (2DG; a glycolytic inhibitor) may stimulate AMPK and lead to AMPK-dependent mTORC1 suppression so that it was used to explore the treatment in a patient with HLRCC. Unfortunately, the patient died shortly after the 2DG treatment. Interestingly, sustained consumption of $2 \mathrm{DG}$ in the patient causes symptoms of hypoglycemia, indicating a significant inhibition of glycolysis (111). Further research is required to verify the feasibility of therapeutic strategies that disturb tumor glycolysis.

\section{CONCLUSIONS AND PERSPECTIVES}

HLRCC is a pathological type of biologically aggressive RCC. HLRCC is triggered by germline mutations in the FH gene that encodes the Krebs cycle enzyme. However, the molecular mechanisms by which FH mutations cause HLRCC are poorly understood. The accumulation of evidence on the molecular mechanisms will make it possible to better understand the pathogenesis of HLRCC. In HLRCC cells, FH loss leads directly to the accumulation of intracellular fumarate, resulting in the activation of multiple signaling pathway components, such as HIF1A, NRF2. Moreover, the accumulation of fumarate weakened the cellular homeostasis of iron. Besides, the accumulation of fumarate attenuated AMPK activity and facilitated a metabolic shift towards aerobic glycolysis.

Although there is still no standard treatment associated with HLRCC, multiple potential therapeutic approaches to address

\section{REFERENCES}

1. Chayed Z, Kristensen LK, Ousager LB, Ronlund K, Bygum A. Hereditary Leiomyomatosis and Renal Cell Carcinoma: A Case Series and Literature Review. Orphanet J Rare Dis (2021) 16(1):34. doi: 10.1186/s13023-02001653-9

2. Wong MH, Tan CS, Lee SC, Yong Y, Ooi AS, Ngeow J, et al. Potential Genetic Anticipation in Hereditary Leiomyomatosis-Renal Cell Cancer (HLRCC). Fam Cancer (2014) 13(2):281-9. doi: 10.1007/s10689-0149703-x

3. El-Zaatari Z, Divatia MK. Hereditary Leiomyomatosis and Renal Cell Carcinoma Syndrome-Associated Renal Cell Carcinoma: Morphological Appraisal With a Comprehensive Review of Differential Diagnoses. Indian J Pathol Microbiol (2020) 63(Supplement):S7-S17. doi: 10.4103/ IJPM.IJPM_877_19

4. Haas NB, Nathanson KL. Hereditary Kidney Cancer Syndromes. Adv Chronic Kidney Dis (2014) 21(1):81-90. doi: 10.1053/j.ackd.2013.10.001

5. Menko FH, Maher ER, Schmidt LS, Middelton LA, Aittomaki K, Tomlinson I, et al. Hereditary Leiomyomatosis and Renal Cell Cancer (HLRCC): Renal Cancer Risk, Surveillance and Treatment. Fam Cancer (2014) 13(4):637-44. doi: 10.1007/s10689-014-9735-2

6. Lehtonen HJ. Hereditary Leiomyomatosis and Renal Cell Cancer: Update on Clinical and Molecular Characteristics. Fam Cancer (2011) 10(2):397-411. doi: 10.1007/s10689-011-9428-z

7. Moch H, Cubilla AL, Humphrey PA, Reuter VE, Ulbright TM. The 2016 WHO Classification of Tumours of the Urinary System and Male Genital Organs-Part a: Renal, Penile, and Testicular Tumours. Eur Urol (2016) 70 (1):93-105. doi: 10.1016/j.eururo.2016.02.029 this early-onset disease are under consideration. Advances in pre-clinical and clinical research at HLRCC are summarized for the first time in this article. The combination of bevacizumab and erlotinib was recommended by NCCN for HLRCC treatment. Also, cabozantinib, a multikinase inhibitor that inhibits specific receptor tyrosine kinases such as VEGFR1, VEGFR2, VEGFR3, KIT, TRKB, FLT-3, AXL, RET, MET, and TIE-2, is an additional underlying option for HLRCC treatment. FDA-approved medications for renal cell carcinoma, such as sunitinib, everolimus, and pazopanib, are not satisfactory for HLRCC patients. Other frontline therapies for renal carcinoma, including ipilimumab combined with nivolumab, axitinib combined with pembrolizumab, and cabozantinib, seem to hold greater promise in HLRCC. Taken together, there will be more alternative treatment options moving forward with a deeper understanding of HLRCC.

\section{AUTHOR CONTRIBUTIONS}

All authors listed have made a substantial, direct and intellectual contribution to the work, and approved it for publication. All authors contributed to the article and approved the submitted version.

\section{FUNDING}

This work was supported by the National Natural Science Foundation of China (81660755) and the Science and Technology Project of Shenzhen of China (JCYJ20170307160524377).

8. Trpkov K, Hes O, Agaimy A, Bonert M, Martinek P, Magi-Galluzzi C, et al. Fumarate Hydratase-deficient Renal Cell Carcinoma Is Strongly Correlated With Fumarate Hydratase Mutation and Hereditary Leiomyomatosis and Renal Cell Carcinoma Syndrome. Am J Surg Pathol (2016) 40(7):865-75. doi: 10.1097/PAS.0000000000000617

9. Schmidt LS, Linehan WM. Hereditary Leiomyomatosis and Renal Cell Carcinoma. Int J Nephrol Renovasc Dis (2014) 7:253-60. doi: 10.2147/ IJNRD.S42097

10. Ooi A. Advances in Hereditary Leiomyomatosis and Renal Cell Carcinoma (HLRCC) Research. Semin Cancer Biol (2020) 61:158-66. doi: 10.1016/ j.semcancer.2019.10.016

11. Ball MW, Ricketts CJ. Complexities in Estimating the True Risk of Hereditary Leiomyomatosis and Renal Cell Carcinoma and the Development of Kidney Cancer. Cancer (2020) 126(16):3617-9. doi: 10.1002/cncr.32915

12. Hol JA, Jongmans MCJ, Littooij AS, de Krijger RR, Kuiper RP, van Harssel JJT, et al. Renal Cell Carcinoma in Young FH Mutation Carriers: Case Series and Review of the Literature. Fam Cancer (2020) 19(1):55-63. doi: 10.1007/ s10689-019-00155-3

13. de Velasco G, Munoz C, Sepulveda JM, Castellano D. Sequential Treatments in Hereditary Leiomyomatosis and Renal Cell Carcinoma (HLRCC): Case Report and Review of the Literature. Can Urol Assoc J (2015) 9(3-4):E243. doi: $10.5489 /$ cuaj.2264

14. Kancherla P, Daneshvar M, Sager RA, Mollapour M, Bratslavsky G. Fumarate Hydratase as a Therapeutic Target in Renal Cancer. Expert Opin Ther Targets (2020) 24(9):923-36. doi: 10.1080/14728222.2020.1804862

15. Dizman N, Philip EJ, Pal SK. Genomic Profiling in Renal Cell Carcinoma. Nat Rev Nephrol (2020) 16(8):435-51. doi: 10.1038/s41581-020-0301-x 
16. Ricketts CJ, De Cubas AA, Fan H, Smith CC, Lang M, Reznik E, et al. The Cancer Genome Atlas Comprehensive Molecular Characterization of Renal Cell Carcinoma. Cell Rep (2018) 23(1):313-26 e5. doi: 10.1016/ j.celrep.2018.03.075

17. Sidana A, Srinivasan R. Therapeutic Strategies for Hereditary Kidney Cancer. Curr Oncol Rep (2016) 18(8):50. doi: 10.1007/s11912-016-0537-6

18. Espana A, Ornilla E, Zarate R, Gil-Bazo I, Briones P. Myopathy in Hereditary Leiomyomatosis and Renal Cell Cancer in an Extended Family. Br J Dermatol (2015) 172(5):1442-5. doi: 10.1111/bjd.13504

19. Tolvanen J, Uimari O, Ryynanen M, Aaltonen LA, Vahteristo P. Strong Family History of Uterine Leiomyomatosis Warrants Fumarate Hydratase Mutation Screening. Hum Reprod (2012) 27(6):1865-9. doi: 10.1093/ humrep/des105

20. Yong C, Stewart GD, Frezza C. Oncometabolites in Renal Cancer. Nat Rev Nephrol (2020) 16(3):156-72. doi: 10.1038/s41581-019-0210-z

21. Linehan WM, Rouault TA. Molecular Pathways: Fumarate HydrataseDeficient Kidney Cancer-Targeting the Warburg Effect in Cancer. Clin Cancer Res (2013) 19(13):3345-52. doi: 10.1158/1078-0432.CCR-13-0304

22. Zheng L, MacKenzie ED, Karim SA, Hedley A, Blyth K, Kalna G, et al. Reversed Argininosuccinate Lyase Activity in Fumarate Hydratase-Deficient Cancer Cells. Cancer Metab (2013) 1(1):12. doi: 10.1186/2049-3002-1-12

23. Schmidt C, Sciacovelli M, Frezza C. Fumarate Hydratase in Cancer: A Multifaceted Tumour Suppressor. Semin Cell Dev Biol (2020) 98:15-25. doi: $10.1016 /$ j.semcdb.2019.05.002

24. Wu LY, He YL, Zhu LL. Possible Role of PHD Inhibitors as HypoxiaMimicking Agents in the Maintenance of Neural Stem Cells' Self-Renewal Properties. Front Cell Dev Biol (2018) 6:169. doi: 10.3389/fcell.2018.00169

25. Sudarshan S, Pinto PA, Neckers L, Linehan WM. Mechanisms of Disease: Hereditary Leiomyomatosis and Renal Cell Cancer-a Distinct Form of Hereditary Kidney Cancer. Nat Clin Pract Urol (2007) 4(2):104-10. doi: 10.1038/ncpuro0711

26. Est-Witte SE, Farris AL, Tzeng SY, Hutton DL, Gong DH, Calabresi KG, et al. Non-Viral Gene Delivery of HIF-1alpha Promotes Angiogenesis in Human Adipose-Derived Stem Cells. Acta Biomater (2020) 113:279-88. doi: 10.1016/j.actbio.2020.06.042

27. Palazon A, Tyrakis PA, Macias D, Velica P, Rundqvist H, Fitzpatrick S, et al. An HIF-1alpha/VEGF-A Axis in Cytotoxic T Cells Regulates Tumor Progression. Cancer Cell (2017) 32(5):669-83 e5. doi: 10.1016/ j.ccell.2017.10.003

28. Fan T, Sun G, Sun X, Zhao L, Zhong R, Peng Y. Tumor Energy Metabolism and Potential of 3-Bromopyruvate as an Inhibitor of Aerobic Glycolysis: Implications in Tumor Treatment. Cancers (2019) 11(3):317. doi: 10.3390/ cancers 11030317

29. Masoud GN, Li W. Hif-1alpha Pathway: Role, Regulation and Intervention for Cancer Therapy. Acta Pharm Sin B (2015) 5(5):378-89. doi: 10.1016/ j.apsb.2015.05.007

30. Moldogazieva NT, Mokhosoev IM, Terentiev AA. Metabolic Heterogeneity of Cancer Cells: An Interplay Between HIF-1, Gluts, and AMPK. Cancers (Basel) (2020) 12(4):862. doi: 10.3390/cancers 12040862

31. Kido T, Murata H, Nishigaki A, Tsubokura H, Komiya S, Kida N, et al. Glucose Transporter 1 is Important for the Glycolytic Metabolism of Human Endometrial Stromal Cells in Hypoxic Environment. Heliyon (2020) 6(6): e03985. doi: 10.1016/j.heliyon.2020.e03985

32. Sudarshan S, Linehan WM, Neckers L. HIF and Fumarate Hydratase in Renal Cancer. Br J Cancer (2007) 96(3):403-7. doi: 10.1038/sj.bjc.6603547

33. Tirpe AA, Gulei D, Ciortea SM, Crivii C, Berindan-Neagoe I. Hypoxia: Overview on Hypoxia-Mediated Mechanisms With a Focus on the Role of HIF Genes. Int J Mol Sci (2019) 20(24):6140. doi: 10.3390/ijms20246140

34. Soni S, Padwad YS. HIF-1 in Cancer Therapy: Two Decade Long Story of a Transcription Factor. Acta Oncol (2017) 56(4):503-15. doi: 10.1080/ 0284186X.2017.1301680

35. Pezzuto A, Carico E. Role of HIF-1 in Cancer Progression: Novel Insights. A Review. Curr Mol Med (2018) 18(6):343-51. doi: 10.2174/ 1566524018666181109121849

36. Yang T, Yao Q, Cao F, Liu Q, Liu B, Wang X-H. Silver Nanoparticles Inhibit the Function of Hypoxia-Inducible Factor-1 and Target Genes: Insight Into the Cytotoxicity and Antiangiogenesis. Int J Nanomed (2016) 11:6679. doi: 10.2147/IJN.S109695
37. Kumari S, Badana AK, Malla R. Reactive Oxygen Species: A Key Constituent in Cancer Survival. Biomarker Insights (2018) 13:1177271918755391. doi: $10.1177 / 1177271918755391$

38. Chen R, Lai UH, Zhu L, Singh A, Ahmed M, Forsyth NR. Reactive Oxygen Species Formation in the Brain At Different Oxygen Levels: The Role of Hypoxia Inducible Factors. Front Cell Dev Biol (2018) 6:132. doi: 10.3389/ fcell.2018.00132

39. Payen VL, Zampieri LX, Porporato PE, Sonveaux P. Pro-and Antitumor Effects of Mitochondrial Reactive Oxygen Species. Cancer Metastasis Rev (2019) 38(1-2):189-203. doi: 10.1007/s10555-019-09789-2

40. Sullivan LB, Gui DY, Vander Heiden MG. Altered Metabolite Levels in Cancer: Implications for Tumour Biology and Cancer Therapy. Nat Rev Cancer (2016) 16(11):680. doi: 10.1038/nrc.2016.85

41. Sajnani K, Islam F, Smith RA, Gopalan V, Lam AK-Y. Genetic Alterations in Krebs Cycle and its Impact on Cancer Pathogenesis. Biochimie (2017) 135:164-72. doi: 10.1016/j.biochi.2017.02.008

42. Lee G, Won H-S, Lee Y-M, Choi J-W, Oh T-I, Jang J-H, et al. Oxidative Dimerization of PHD2 is Responsible for its Inactivation and Contributes to Metabolic Reprogramming Via HIF-1 $\alpha$ Activation. Sci Rep (2016) 6(1):1-12. doi: $10.1038 /$ srep 18928

43. Haase VH. HIF-Prolyl Hydroxylases as Therapeutic Targets in Erythropoiesis and Iron Metabolism. Hemodial Int (2017) 21:S110-S24. doi: $10.1111 /$ hdi.12567

44. Georgakopoulos-Soares I, Chartoumpekis DV, Kyriazopoulou V, Zaravinos A. EMT Factors and Metabolic Pathways in Cancer. Front Oncol (2020) 10:499. doi: 10.3389/fonc.2020.00499

45. Kang H, Kim H, Lee S, Youn H, Youn B. Role of Metabolic Reprogramming in Epithelial-Mesenchymal Transition (EMT). Int J Mol Sci (2019) 20 (8):2042. doi: 10.3390/ijms20082042

46. Teoh ST, Lunt SY. Metabolism in Cancer Metastasis: Bioenergetics, Biosynthesis, and Beyond. Wiley Interdiscip Rev: Syst Biol Med (2018) 10 (2):e1406. doi: 10.1002/wsbm.1406

47. Sciacovelli M, Goncalves E, Johnson TI, Zecchini VR, da Costa AS, Gaude E, et al. Fumarate is an Epigenetic Modifier That Elicits Epithelial-toMesenchymal Transition. Nature (2016) 537(7621):544-7. doi: 10.1038/ nature19353

48. Thomas LW, Ashcroft M. Exploring the Molecular Interface Between Hypoxia-Inducible Factor Signalling and Mitochondria. Cell Mol Life Sci (2019) 76(9):1759-77. doi: 10.1007/s00018-019-03039-y

49. Sciacovelli M, Frezza C. Fumarate Drives EMT in Renal Cancer. Cell Death Differ (2017) 24(1):1-2. doi: 10.1038/cdd.2016.137

50. Koivunen P, Laukka T. The TET Enzymes. Cell Mol Life Sci (2018) 75 (8):1339-48. doi: 10.1007/s00018-017-2721-8

51. Laukka T, Mariani CJ, Ihantola T, Cao JZ, Hokkanen J, Kaelin WG, et al. Fumarate and Succinate Regulate Expression of Hypoxia-Inducible Genes Via TET Enzymes. J Biol Chem (2016) 291(8):4256-65. doi: 10.1074/ jbc.M115.688762

52. Janin M, Esteller M. Oncometabolite Accumulation and Epithelial-toMesenchymal Transition: The Turn of Fumarate. Cell Metab (2016) 24 (4):529-30. doi: 10.1016/j.cmet.2016.09.020

53. Morandi A, Taddei ML, Chiarugi P, Giannoni E. Targeting the Metabolic Reprogramming That Controls Epithelial-to-Mesenchymal Transition in Aggressive Tumors. Front Oncol (2017) 7:40. doi: 10.3389/fonc.2017.00040

54. De Craene B, Berx G. Regulatory Networks Defining EMT During Cancer Initiation and Progression. Nat Rev Cancer (2013) 13(2):97-110. doi: $10.1038 / \mathrm{nrc} 3447$

55. Uckelmann M, Sixma TK. Histone Ubiquitination in the DNA Damage Response. DNA Repair (2017) 56:92-101. doi: 10.1016/j.dnarep.2017.06.011

56. Leshets M, Silas YB, Lehming N, Pines O. Fumarase: From the TCA Cycle to DNA Damage Response and Tumor Suppression. Front Mol Biosci (2018) 5:68. doi: $10.3389 / \mathrm{fmolb} .2018 .00068$

57. Dutta A, Yang C, Sengupta S, Mitra S, Hegde ML. New Paradigms in the Repair of Oxidative Damage in Human Genome: Mechanisms Ensuring Repair of Mutagenic Base Lesions During Replication and Involvement of Accessory Proteins. Cell Mol Life Sci (2015) 72(9):1679-98. doi: 10.1007/s00018-014-1820-z

58. Johnson TI, Costa ASH, Ferguson AN, Frezza C. Fumarate Hydratase Loss Promotes Mitotic Entry in the Presence of DNA Damage After Ionising Radiation. Cell Death Dis (2018) 9(9):913. doi: 10.1038/s41419-018-0912-3 
59. Saatchi F, Kirchmaier AL. Tolerance of DNA Replication Stress is Promoted by Fumarate Through Modulation of Histone Demethylation and Enhancement of Replicative Intermediate Processing in Saccharomyces Cerevisiae. Genetics (2019) 212(3):631-54. doi: 10.1534/genetics.119.302238

60. Leshets M, Ramamurthy D, Lisby M, Lehming N, Pines O. Fumarase is Involved in DNA Double-Strand Break Resection Through a Functional Interaction With Sae2. Curr Genet (2018) 64(3):697-712. doi: 10.1007/ s00294-017-0786-4

61. Sulkowski PL, Sundaram RK, Oeck S, Corso CD, Liu Y, Noorbakhsh S, et al. Krebs-Cycle-Deficient Hereditary Cancer Syndromes are Defined by Defects in Homologous-Recombination DNA Repair. Nat Genet (2018) 50(8):108692. doi: 10.1038/s41588-018-0170-4

62. Yogev O, Yogev O, Singer E, Shaulian E, Goldberg M, Fox TD, et al. Fumarase: A Mitochondrial Metabolic Enzyme and a Cytosolic/Nuclear Component of the DNA Damage Response. PloS Biol (2010) 8(3):e1000328. doi: 10.1371/journal.pbio.1000328

63. Jiang Y, Qian X, Shen J, Wang Y, Li X, Liu R, et al. Author Correction: Local Generation of Fumarate Promotes DNA Repair Through Inhibition of Histone H3 Demethylation. Nat Cell Biol (2018) 20(10):1226. doi: 10.1038/s41556-018-0074-7

64. Xiang Y, Yan K, Zheng Q, Ke H, Cheng J, Xiong W, et al. Histone Demethylase Kdm4b Promotes Dna Damage by Activating Long Interspersed Nuclear Element-1. Cancer Res (2019) 79(1):86-98. doi: 10.1158/0008-5472.CAN-18-1310

65. Panieri E, Telkoparan-Akillilar P, Suzen S, Saso L. The NRF2/KEAP1 Axis in the Regulation of Tumor Metabolism: Mechanisms and Therapeutic Perspectives. Biomolecules (2020) 10(5):791. doi: 10.3390/biom10050791

66. Kansanen E, Kuosmanen SM, Leinonen H, Levonen AL. The Keap1-Nrf2 Pathway: Mechanisms of Activation and Dysregulation in Cancer. Redox Biol (2013) 1:45-9. doi: 10.1016/j.redox.2012.10.001

67. Chen YB, Brannon AR, Toubaji A, Dudas ME, Won HH, Al-Ahmadie HA, et al. Hereditary Leiomyomatosis and Renal Cell Carcinoma SyndromeAssociated Renal Cancer: Recognition of the Syndrome by Pathologic Features and the Utility of Detecting Aberrant Succination by Immunohistochemistry. Am J Surg Pathol (2014) 38(5):627-37. doi: 10.1097/PAS.0000000000000163

68. Skala SL, Dhanasekaran SM, Mehra R. Hereditary Leiomyomatosis and Renal Cell Carcinoma Syndrome (Hlrcc): A Contemporary Review and Practical Discussion of the Differential Diagnosis for HLRCC-Associated Renal Cell Carcinoma. Arch Pathol Lab Med (2018) 142(10):1202-15. doi: 10.5858/arpa.2018-0216-RA

69. Serafini MM, Catanzaro M, Fagiani F, Simoni E, Caporaso R, Dacrema M, et al. Modulation of Keap1/Nrf2/ARE Signaling Pathway by Curcuma- and Garlic-Derived Hybrids. Front Pharmacol (2019) 10:1597. doi: 10.3389/ fphar.2019.01597

70. Panieri E, Buha A, Telkoparan-Akillilar P, Cevik D, Kouretas D, Veskoukis A, et al. Potential Applications of NRF2 Modulators in Cancer Therapy. Antioxid (Basel) (2020) 9(3):193. doi: 10.3390/antiox9030193

71. Zimta AA, Cenariu D, Irimie A, Magdo L, Nabavi SM, Atanasov AG, et al. The Role of Nrf2 Activity in Cancer Development and Progression. Cancers (Basel) (2019) 11(11):1755. doi: 10.3390/cancers11111755

72. Li L, Dong H, Song E, Xu X, Liu L, Song Y. Nrf2/ARE Pathway Activation, HO-1 and NQO1 Induction by Polychlorinated Biphenyl Quinone is Associated With Reactive Oxygen Species and PI3K/AKT Signaling. Chem Biol Interact (2014) 209:56-67. doi: 10.1016/j.cbi.2013.12.005

73. Kubo E, Chhunchha B, Singh P, Sasaki H, Singh DP. Sulforaphane Reactivates Cellular Antioxidant Defense by Inducing Nrf2/ARE/Prdx6 Activity During Aging and Oxidative Stress. Sci Rep (2017) 7(1):14130. doi: 10.1038/s41598-017-14520-8

74. Chhunchha B, Kubo E, Singh DP. Clock Protein Bmall and Nrf2 Cooperatively Control Aging or Oxidative Response and Redox Homeostasis by Regulating Rhythmic Expression of Prdx6. Cells (2020) 9 (8):1861. doi: 10.3390/cells9081861

75. Scagliola A, Mainini F, Cardaci S. The Tricarboxylic Acid Cycle At the Crossroad Between Cancer and Immunity. Antioxid Redox Signal (2020) 32 (12):834-52. doi: 10.1089/ars.2019.7974

76. Sandhu IS, Maksim NJ, Amouzougan EA, Gallion BW, Raviele AL, Ooi A. Sustained NRF2 Activation in Hereditary Leiomyomatosis and Renal Cell
Cancer (HLRCC) and in Hereditary Tyrosinemia Type 1 (HT1). Biochem Soc Trans (2015) 43(4):650-6. doi: 10.1042/BST20150041

77. Ooi A, Dykema K, Ansari A, Petillo D, Snider J, Kahnoski R, et al. CUL3 and NRF2 Mutations Confer an NRF2 Activation Phenotype in a Sporadic Form of Papillary Renal Cell Carcinoma. Cancer Res (2013) 73(7):2044-51. doi: 10.1158/0008-5472.CAN-12-3227

78. Choi Y, Keam B, Kim M, Yoon S, Kim D, Choi JG, et al. Bevacizumab Plus Erlotinib Combination Therapy for Advanced Hereditary Leiomyomatosis and Renal Cell Carcinoma-Associated Renal Cell Carcinoma: A Multicenter Retrospective Analysis in Korean Patients. Cancer Res Treat (2019) 51 (4):1549-56. doi: 10.4143/crt.2019.086

79. Srinivasan R, Gurram S, Harthy MA, Singer EA, Sidana A, Shuch BM, et al. Results From a Phase II Study of Bevacizumab and Erlotinib in Subjects With Advanced Hereditary Leiomyomatosis and Renal Cell Cancer (HLRCC) or Sporadic Papillary Renal Cell Cancer. J Clin Oncol (2020) 38 (15_suppl):5004-. doi: 10.1200/JCO.2020.38.15_suppl.5004

80. Park I, Shim YS, Go H, Hong BS, Lee JL. Long-Term Response of Metastatic Hereditary Leiomyomatosis and Renal Cell Carcinoma Syndrome Associated Renal Cell Carcinoma to Bevacizumab Plus Erlotinib After Temsirolimus and Axitinib Treatment Failures. BMC Urol (2019) 19 (1):51. doi: 10.1186/s12894-019-0484-2

81. Lord CJ, Ashworth A. PARP Inhibitors: Synthetic Lethality in the Clinic. Science (2017) 355(6330):1152-8. doi: 10.1126/science.aam7344

82. Li H, Liu ZY, Wu N, Chen YC, Cheng Q, Wang J. PARP Inhibitor Resistance: The Underlying Mechanisms and Clinical Implications. Mol Cancer (2020) 19(1):107. doi: 10.1186/s12943-020-01227-0

83. Li X, Heyer WD. Homologous Recombination in DNA Repair and DNA Damage Tolerance. Cell Res (2008) 18(1):99-113. doi: 10.1038/cr.2008.1

84. Lord CJ, Ashworth A. Brcaness Revisited. Nat Rev Cancer (2016) 16(2):11020. doi: $10.1038 / \mathrm{nrc} .2015 .21$

85. Watkins JA, Irshad S, Grigoriadis A, Tutt AN. Genomic Scars as Biomarkers of Homologous Recombination Deficiency and Drug Response in Breast and Ovarian Cancers. Breast Cancer Res (2014) 16 (3):211. doi: $10.1186 / \mathrm{bcr} 3670$

86. Hoppe MM, Sundar R, Tan DSP, Jeyasekharan AD. Biomarkers for Homologous Recombination Deficiency in Cancer. J Natl Cancer Inst (2018) 110(7):704-13. doi: 10.1093/jnci/djy085

87. Pennington KP, Walsh T, Harrell MI, Lee MK, Pennil CC, Rendi MH, et al. Germline and Somatic Mutations in Homologous Recombination Genes Predict Platinum Response and Survival in Ovarian, Fallopian Tube, and Peritoneal Carcinomas. Clin Cancer Res (2014) 20(3):764-75. doi: 10.1158/ 1078-0432.CCR-13-2287

88. Lallo A, Frese KK, Morrow CJ, Sloane R, Gulati S, Schenk MW, et al. The Combination of the PARP Inhibitor Olaparib and the WEE1 Inhibitor AZD1775 as a New Therapeutic Option for Small Cell Lung Cancer. Clin Cancer Res (2018) 24(20):5153-64. doi: 10.1158/1078-0432.CCR-17-2805

89. Adam J, Yang M, Soga T, Pollard PJ. Rare Insights Into Cancer Biology. Oncogene (2014) 33(20):2547-56. doi: 10.1038/onc.2013.222

90. Schaefer IM, Hornick JL, Bovee J. The Role of Metabolic Enzymes in Mesenchymal Tumors and Tumor Syndromes: Genetics, Pathology, and Molecular Mechanisms. Lab Invest (2018) 98(4):414-26. doi: 10.1038/ s41374-017-0003-6

91. Dawson MA. The Cancer Epigenome: Concepts, Challenges, and Therapeutic Opportunities. Science (2017) 355(6330):1147-52. doi: $10.1126 /$ science.aam 7304

92. Mahmoud AM, Ali MM. Methyl Donor Micronutrients That Modify DNA Methylation and Cancer Outcome. Nutrients (2019) 11(3):608. doi: 10.3390/ nu11030608

93. Kadayifci FZ, Zheng S, Pan Y-X. Molecular Mechanisms Underlying the Link Between Diet and DNA Methylation. Int J Mol Sci (2018) 19(12):4055. doi: $10.3390 / \mathrm{ijms} 19124055$

94. Castillo-Aguilera O, Depreux P, Halby L, Arimondo PB, Goossens L. DNA Methylation Targeting: The DNMT/HMT Crosstalk Challenge. Biomolecules (2017) 7(1):3. doi: 10.3390/biom7010003

95. Daher-Reyes GS, Merchan BM, Yee KW. Guadecitabine (SGI-110): An Investigational Drug for the Treatment of Myelodysplastic Syndrome and Acute Myeloid Leukemia. Expert Opin Invest Drugs (2019) 28(10):835-49. doi: $10.1080 / 13543784.2019 .1667331$ 
96. Wong KK, Lawrie CH, Green TM. Oncogenic Roles and Inhibitors of DNMT1, DNMT3A, and DNMT3B in Acute Myeloid Leukaemia. Biomarker Insights (2019) 14:1177271919846454. doi: 10.1177/1177271919846454

97. Wedekind MF, Rivero JD, Arnaldez FI, Srinivasan R, Spencer M, Steinberg SM, et al. A Phase II Trial of the DNA Methyl Transferase Inhibitor, SGI-110 (Guadecitabine), in Children and Adults With SDH-deficient GIST, Pheochromocytoma, and Paraganglioma, and HLRCC-associated Kidney Cancer. J Clin Oncol (2020) 38(15_suppl):11540-. doi: 10.1200/ JCO.2020.38.15_suppl.11540

98. Sourbier C, Ricketts CJ, Matsumoto S, Crooks DR, Liao PJ, Mannes PZ, et al. Targeting ABL1-mediated Oxidative Stress Adaptation in Fumarate Hydratase-Deficient Cancer. Cancer Cell (2014) 26(6):840-50. doi: 10.1016/j.ccell.2014.10.005

99. Levinson NM, Boxer SG. Structural and Spectroscopic Analysis of the Kinase Inhibitor Bosutinib and an Isomer of Bosutinib Binding to the Abl Tyrosine Kinase Domain. PloS One (2012) 7(4):e29828. doi: 10.1371/journal.pone.0029828

100. Braun TP, Eide CA, Druker BJ. Response and Resistance to BCR-ABL1Targeted Therapies. Cancer Cell (2020) 37(4):530-42. doi: 10.1016/ j.ccell.2020.03.006

101. Massimino M, Stella S, Tirro E, Romano C, Pennisi MS, Puma A, et al. Non ABL-directed Inhibitors as Alternative Treatment Strategies for Chronic Myeloid Leukemia. Mol Cancer (2018) 17(1):56. doi: 10.1186/s12943-0180805-1

102. Xu W, Atkins MB, McDermott DF. Checkpoint Inhibitor Immunotherapy in Kidney Cancer. Nat Rev Urol (2020) 17(3):137-50. doi: 10.1038/s41585-0200282-3

103. Aggen DH, Drake CG, Rini BI. Targeting PD-1 or PD-L1 in Metastatic Kidney Cancer: Combination Therapy in the First-Line Setting. Clin Cancer Res (2020) 26(9):2087-95. doi: 10.1158/1078-0432.CCR-19-3323

104. Lalani AA, McGregor BA, Albiges L, Choueiri TK, Motzer R, Powles T, et al. Systemic Treatment of Metastatic Clear Cell Renal Cell Carcinoma in 2018: Current Paradigms, Use of Immunotherapy, and Future Directions. Eur Urol (2019) 75(1):100-10. doi: 10.1016/j.eururo.2018.10.010

105. Alaghehbandan R, Stehlik J, Trpkov K, Magi-Galluzzi C, Condom Mundo E, Pane Foix M, et al. Programmed Death-1 (PD-1) Receptor/PD-1 Ligand (PD-L1) Expression in Fumarate Hydratase-Deficient Renal Cell Carcinoma. Ann Diagn Pathol (2017) 29:17-22. doi: 10.1016/j.anndiagpath.2017.04.007
106. Yonese I, Ito M, Takemura K, Kamai T, Koga F. A Case of Metastatic Hereditary Leiomyomatosis and Renal Cell Cancer Syndrome-Associated Renal Cell Carcinoma Treated With a Sequence of Axitinib and Nivolumab Following Cytoreductive Nephrectomy. J Kidney Cancer VHL (2020) 7:6-10. doi: $10.15586 / \mathrm{jkcvhl} .2020 .148$

107. Feng D, Yang Y, Han P, Wei X. The Preliminary Outcome of the Combination of Immunotherapy and Targeted Therapy After Recurrence and Metastasis for Hereditary Leiomyomatosis and Renal Cell Cancer-a Case Report. Transl Androl Urol (2020) 9(2):789-93. doi: 10.21037/tau.2019.12.37

108. Iribe Y, Furuya M, Shibata Y, Yasui M, Funahashi M, Ota J, et al. Complete Response of Hereditary Leiomyomatosis and Renal Cell Cancer (HLRCC)Associated Renal Cell Carcinoma to Nivolumab and Ipilimumab Combination Immunotherapy by: A Case Report. Fam Cancer (2020). doi: 10.1007/s10689-020-00195-0

109. Wei SC, Duffy CR, Allison JP. Fundamental Mechanisms of Immune Checkpoint Blockade Therapy. Cancer Discovery (2018) 8(9):1069-86. doi: 10.1158/2159-8290.CD-18-0367

110. Martinez Chanza N, Xie W, Asim Bilen M, Dzimitrowicz H, Burkart J, Geynisman DM, et al. Cabozantinib in Advanced non-Clear-Cell Renal Cell Carcinoma: A Multicentre, Retrospective, Cohort Study. Lancet Oncol (2019) 20(4):581-90. doi: 10.1016/S1470-2045(18)30907-0

111. Yamasaki T, Tran TA, Oz OK, Raj GV, Schwarz RE, Deberardinis RJ, et al. Exploring a Glycolytic Inhibitor for the Treatment of an FH-deficient Type-2 Papillary RCC. Nat Rev Urol (2011) 8(3):165-71. doi: 10.1038/ nrurol.2010.234

Conflict of Interest: The authors declare that the research was conducted in the absence of any commercial or financial relationships that could be construed as a potential conflict of interest.

Copyright (c) 2021 Zhang, Li, Zhang and Zeng. This is an open-access article distributed under the terms of the Creative Commons Attribution License (CC BY). The use, distribution or reproduction in other forums is permitted, provided the original author(s) and the copyright owner(s) are credited and that the original publication in this journal is cited, in accordance with accepted academic practice. No use, distribution or reproduction is permitted which does not comply with these terms. 
GLOSSARY

HLRCC
RCC
FH
LRCC
WHO
VEGFR
TKls
mTOR
TCA
HIF
PHD
EPO
EGF
TGF- $\beta 3$
GLUTs
O2
2-OG
ODD
pVHL
Fe2+
Fe3+
EMT
TET
$5-h m C$
DNA-PKcs
NHEJ
HR
KEAP1
Nrf2

hereditary leiomyomatosis and renal

cell carcinoma

renal cell carcinoma

fumarate hydratase

leiomyomatosis and renal cell cancer

Worldwide health organization

vascular endothelial growth factor receptor

tyrosine kinase inhibitors

mammalian target of rapamycin

tricarboxylic acid

hypoxia-inducible factor

prolyl hydroxylase

erythropoietin

epidermal growth factor

transforming growth factor beta3

glucose transporters

oxygen

2-oxoglutarate

oxygen-dependent degradation domain

Von Hippel-Lindau tumor suppressor protein

Ferrous iron

Ferric form

Epithelial-mesenchymal transition

Ten-Eleven Translocation

5-hydroxymethylcytosine

DNA-PK catalytic subunit

non-homologous end joining

homologous recombination

Kelch-like $\mathrm{ECH}$-associated protein 1

nuclear factor E2-related factor 2
Continued

$\begin{array}{ll}\text { NFE2L2 } & \text { nuclear factor, erythroid derivative two like } 2 \\ \text { bZIP } & \text { basic leucine zipper } \\ \text { ARE } & \text { antioxidant response } \\ \text { ROS } & \text { reactive-oxygen species } \\ \text { Prdx1 } & \text { peroxiredoxin 1 } \\ \text { HO-1 } & \text { heme oxygenase-1 } \\ \text { SOD-1 } & \text { superoxide dismutase-1 } \\ \text { NQO1 } & \text { NAD(P)H dehydrogenase quinone 1 } \\ \text { GCLM } & \text { glutamate-cysteine ligase modifier } \\ \text { GSTs } & \text { glutathione S-transferases } \\ \text { VEGF } & \text { vascular endothelial growth factor } \\ \text { TGF- } \alpha & \text { transforming growth factor-alpha } \\ \text { EGFR } & \text { epidermal growth factor receptor } \\ \text { ORR } & \text { objective response rate } \\ \text { NCCN } & \text { National Comprehensive Cancer Network } \\ \text { PFS } & \text { progression-free survival } \\ \text { Cl } & \text { confidence interval } \\ \text { BER } & \text { base excision repair } \\ \text { SSBs } & \text { single-strand breaks } \\ \text { DSBs } & \text { double-strand breaks } \\ \text { PARP } & \text { poly (ADP-ribose) polymerase } \\ \text { HRD } & \text { homologous recombination deficiency } \\ 5 \text { mC } & \text { DNA 5-methylcytosine } \\ \text { DNMT } & \text { DNA methyltransferases } \\ \text { RET } & \text { Ret Proto-Oncogene } \\ \text { RTK } & \text { receptor tyrosine kinase } \\ \text { ABL1 } & \text { ABL proto-oncogene 1, non-receptor tyrosine kinase } \\ \text { SIRT1 } & \text { silent information regulator T1 } \\ \text { AMPK } & \text { AMP-activated protein kinase } \\ \text { FDA } & \text { Food and Drug Administration } \\ \text { IHC } & \text { immunohistochemistry } \\ \text { qPCR } & \text { quantitative polymerase chain reaction } \\ \text { 2DG } & \text {-deoxy-D-glucose } \\ & \end{array}$

